$68.5 \%(n=37)$ in PsA and $45.7 \%(n=21)$ in PsO. US synovitis was more frequently found than clinical assessment. The most common sites of inflammatory synovitis were the wrist. US enthesopathy was found in $87.0 \%(n=47)$ in patients with PsA $56.5 \%(n=26)$ in patients with PsO. US enthesitis was also more frequently found than clinical assessment. The most common sites of enthesopathy were the enthesis in lateral epicondyle, quadriceps and Achilles tendon.

Conclusions: Our results showed that US was able to detect a high prevalence of inflammatory synovitis in peripheral joints and enthesis in patients with PsA. Moreover, subclinical inflammatory findings were also found in patients with PsO by US. US examination is useful to detect the inflammatory condition in patients with PsA and PsO than clinical examination.

Acknowledgements: We wish to thank Setsuko Takeda, Ayumi Hashimoto and Emi Yamashita for their special efforts as a sonographer and collecting data. Disclosure of Interest: None declared

DOI: 10.1136/annrheumdis-2017-eular.5028

\section{SAT0478 RAPID3 QUESTIONNAIRE HAS HIGH DISCRIMINATING ABILITY IN MINIMAL DISEASE ACTIVITY ATTAINMENT IN PATIENTS WITH EARLY PSORIATIC ARTHRITIS TREATED ACCORDING TO TIGHT CONTROL STRATEGY IN DAILY CLINICAL PRACTICE (RESULTS OF ONE-YEAR OPEN-LABEL REMARCA STUDY)}

T. Korotaeva, E. Loginova, A. Koltakova, L. Denisov, M. Chamurlieva, D. Karateev, E. Nasonov. V.A.Nasonova Research Institute of Rheumatology, Moscow, Russian Federation

Background: RAPID3 is an instrument based on patient's report outcomes (PROs) for the assessment of remission and disease activity in rheumatoid arthritis. The advantages of this questionnaire in treat-to-target (T2T) strategy in early psoriatic arthritis (EPSA) have not been studied properly.

Objectives: to study discriminating ability of RAPID3 in minimal disease activity (MDA) attainment in patients with EPsA treated during one year according to tight control strategy.

Methods: $61(\mathrm{M} / \mathrm{F}-29 / 32)$ patients (pts) with active EPsA, according to CASPAR criteria, mean age $37 \pm 10.6$ years, PsA duration $11.3 \pm 10.2$ months, psoriasis duration $75.4 \pm 80.9$ months were included. All pts signed a consent form for participation in the open-label REMARCA study. At baseline and after 1year (yr.) of therapy all pts underwent evaluation of PsA activity by Tender Joint count (TJC78), Swollen Joint Count (SJC76), physician's global disease activity (PhGA) VAS, DAS, CRP (mg/l) and by PROs - patient pain global assessment VAS, Patient global disease activity (PGA) VAS, Health Assessment Questionnaire (HAQ) and RAPID3. The dose of Methotrexate (MTX) subcutaneous (s/c) was escalated by $5 \mathrm{mg}$ every 2 weeks from $10 \mathrm{mg} / \mathrm{wk}$ up to $20-25 \mathrm{mg} / \mathrm{wk}$. If pts did not achieve MDA after 3-6 months of MTX mono-therapy, combination therapy (CoT) of MTX+Adalimumab (ADA) was started in a standard regime; CoT was continued up to $1 \mathrm{yr}$. The proportion of pts who achieved MDA was calculated. M $\pm \mathrm{SD}, \mathrm{Me}$ [Q25;Q75], \%, Spearman rank correlation R, W-test, U-test, ROC-curve analysis were performed. All $p<0.05$ were considered to indicate statistical significance.

Results: By 1 yr. of therapy 36 out of 61 pts (59\%) and 25 out of 61 pts (41\%) were treated with MTX and with MTX+ADA accordingly. Significant improvements in PsA activity and PROs from baseline up to $1 \mathrm{yr}$. were observed: DAS 3.93 [3.20-4.58]/1.36 [0.82-2.25], SJC 7 [5-11]/1 [0-3], TJC 8 [6-1]/1 [0-3], PhGA 56 [48-69]/10 [5-20] and VAS pain 54 [48-68]/11 [1-20], PGA 55 [49-68]/14 [7-24], HAQ $0.75[0.50-1] / 0[0-0.63]$ accordingly (for all W-test $p<0.001$ ). Significant positive correlations between RAPID3 and PsA activity, PROs and CRP are shown in table 1 (for all $R p<0.001$ ).

MDA was seen in 43 out of $61 \%$ pts $(70.5 \%)$. At the same time RAPID3 and CRP significantly decreased from 12.7 [9.2-16.8] to 4.3 [2.0-7.8] and from 16.6 [8.6-34.6] to $2.1[0.9-6.7] \mathrm{mg} / \mathrm{l}$ accordingly (for all W-test, $\mathrm{p}<0.001$ ). Among those who have achieved MDA RAPID3 was in "near remission" status and significantly

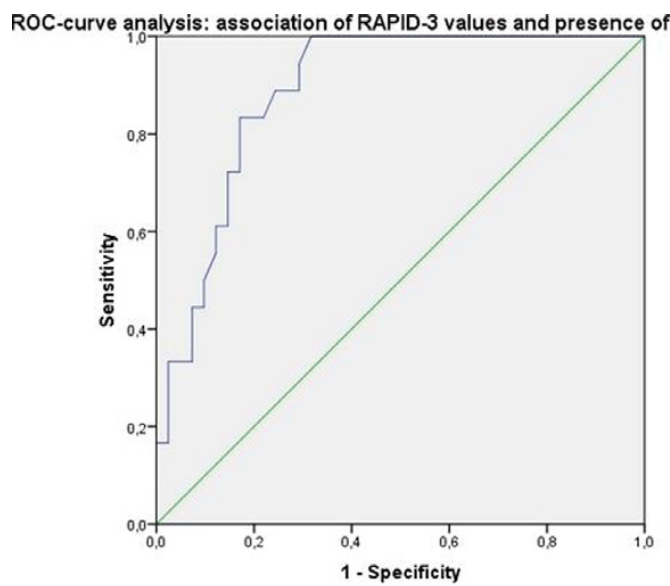

Diagonal segments are produced by ties

\begin{tabular}{lc}
\hline Parameters & $\mathrm{R}$ \\
\hline DAS & 0.74 \\
TJC78 & 0.68 \\
SJC76 & 0.63 \\
PGA VAS & 0.82 \\
Pain VAS & 0.83 \\
PtGA VAS & 0.81 \\
CRP & 0.69 \\
\hline
\end{tabular}

less compared to pts that did not achieve MDA-2.5 [1.3-5.3] and 8.1 [6.0-15.1] accordingly (U-test, $\mathrm{p}<0.001$ ). According to the results of ROC-curve analysis RAPID3 score had a high discriminating ability for the presence of MDA - AUC 0.888 [0.808-0.969] (Fig. 1).

Conclusions: RAPID3 based on PROs is a simple instrument for evaluating PsA activity. RAPID3 has shown high discriminating ability in MDA attainment in EPsA pts treated according to tight-control strategy, and could be useful in daily clinical practice.

Disclosure of Interest: None declared

DOI: 10.1136/annrheumdis-2017-eular.3010

\section{SAT0479 INCREASED CAROTID INTIMA-MEDIA THICKNESS CAN DISCRIMINATE SIGNIFICANT CORONARY ARTERY STENOSIS BY CORONARY CT ANGIOGRAM IN PATIENTS WITH PSORIATIC ARTHRITIS}

T.H. Cheng ${ }^{1}$, Q. Shang ${ }^{1}$, E.K.M. Li ${ }^{1}$, K.T. Wong ${ }^{2}$, A.P.W. Lee ${ }^{1}$, C.C. Szeto ${ }^{1}$, L.S. Tam ${ }^{1} .{ }^{1}$ Department of Medicine and Therapeutics, the Chinese University of Hong Kong; ${ }^{2}$ Department of Diagnostic and Interventional Radiology, The Prince of Wales Hospital, Hong Kong, Hong Kong

Background: PsA patients have increased morbidity \& mortality due to cardiovascular disease (CVD). However, their CV risk were underestimated by various $\mathrm{CV}$ risk score ${ }^{1}$. Subclinical carotid atherosclerosis may be considered as surrogate marker of coronary artery disease (CAD) in the general population ${ }^{2}$ while it remained uncertain for PsA patients

Objectives: To assess the relationship between carotid artery disease by ultrasound (US) and CAD by coronary computed tomography angiography (CCTA) and identify US parameters predictive of significant CAD

Methods: 91 subjects (56 males; age: $50 \pm 11$ years; disease duration $9.4 \pm 9.2$ years) without overt CVD who underwent CCTA \& carotid US (interval between two exams:2 [1-7] months) were recruited. Carotid intima-media thickness (cIMT)\& the presence of plaque were determined by high resolution US in the distal CCA, bulb \& proximal ICA bilaterally. Significant coronary artery stenosis was defined as stenosis of the lumen $>50 \%$

Results: Carotid plaque was present in $33(36 \%)$ patients \& coronary plaque was present in $55(60 \%)$ patients while $9(10 \%)$ patients had significant coronary artery stenosis. $36(40 \%)$ patients had non-zero calcium score (CAC+ group). The mean CIMT was significantly higher in $\mathrm{CAC}+$ group compared to $\mathrm{CAC}=0$ group $[0.70 \pm 0.11 \mathrm{~mm}$ vs $0.64 \pm 0.11 \mathrm{~mm}, p=0.031]$. There was a trend suggesting the mean CIMT increases with increasing CAC score, while the prevalence of carotid plaque increased significantly with rising calcium score (Table1). The mean cIMT increased significantly with number of coronary vessels habouring plaque, while there was a trend suggesting the max cIMT and the prevalence of carotid plaque may increase in patients with rising number of coronary vessels harboring plaques The mean \& max cIMT were significantly higher in SS+ group than SS- group [mean cIMT: $0.76 \pm 0.07 \mathrm{~mm}$ vs0.65 $\pm 0.12 \mathrm{~mm}, p=0.011 ; \max$ cIMT: $0.93 \pm 0.14 \mathrm{~mm}$ vs $0.80 \pm 0.16 \mathrm{~mm}, p=0.020$ ] (Table1). The prevalence of carotid plaque was similar between SS+ \& SS- group [29 (35.4\%) vs $4(44.4 \%), p=0.421]$. Using multivariate logistic regression, mean \& max cIMT were independent explanatory variable of significant coronary stenosis after adjusting age, gender, disease duration \& damaged joint count. The OR of significant coronary stenosis of every $0.01 \mathrm{~mm}$ increase in mean \& max cIMT were $1.07(95 \% \mathrm{Cl}: 1.00-1.15, p=0.042)$ and 1.06 $(95 \% \mathrm{Cl}: 1.00-1.11, p=0.036)$. Mean cIMT of $0.66 \mathrm{~mm}$ was the optimal cut off

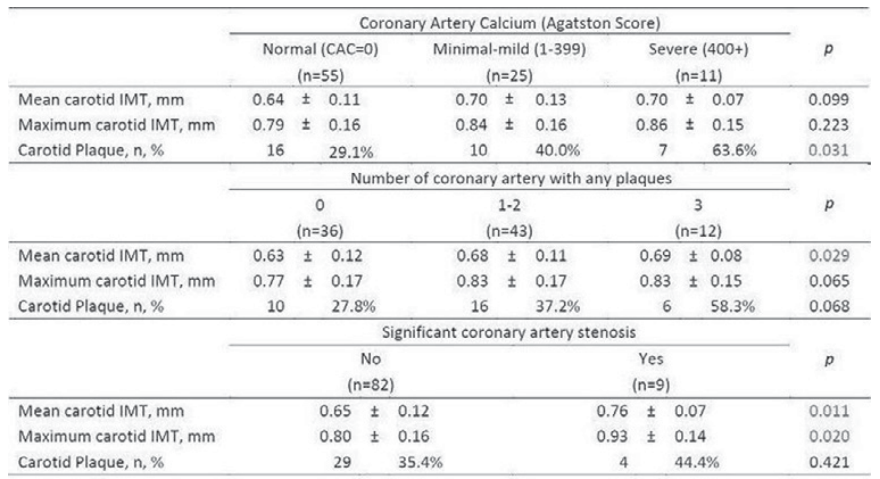

Table 1. Relationship between carotid artery disease by ultrasound and coronary artery disease by coronary computed tomography angiography. 
for discriminating patients with significant coronary stenosis (sensitivity: 100\%; specificity: $44 \%$ ). ROC analyses demonstrated that mean cIMT (AUC $=0.801$, $p=0.003$ )has higher power than Framingham CVD risk score (FRS) (AUC $=0.756$, $p=0.012$ )

Conclusions: Increased cIMT is associated with the presence \& severity of coronary calcification \& obstructive coronary disease on CCTA in PSA patients. CIMT measurement can discriminate PsA patient with significant coronary stenosis better than FRS. PsA patients with moderate CVD risk should have carotid US for better CV risk stratification

\section{References:}

[1] LamHM, ShenJ., et al., Framingham Risk Score Discriminates Coronary Atherosclerosis in PsA Patient Better Than Other Cardiovascular Scores Do [abstract]. Arthritis Rheumatol. 2016;68.

[2] Cohen, G.l., et al., Relationship between carotid disease on ultrasound and coronary disease on CT angiography. JACC Cardiovasc Imaging, 2013.6(11).

Disclosure of Interest: None declared

DOI: 10.1136/annrheumdis-2017-eular.1473

\section{SAT0480 COMPARATIVE EFFECTIVENESS OF SECUKINUMAB AND INFLIXIMAB IN PSORIATIC ARTHRITIS ASSESSED BY MATCHING-ADJUSTED INDIRECT COMPARISON USING PIVOTAL PHASE 3 CLINICAL TRIAL DATA}

V. Strand ${ }^{1}$, I. McInnes ${ }^{2}$, P. Mease ${ }^{3}$, E. Choy ${ }^{4}$, P. Nash ${ }^{5}$, H. Thom ${ }^{6}$ C. Kalyvas ${ }^{7}$, K. Gandhi ${ }^{8}$, L. Pricop ${ }^{8}$, S. Jugl ${ }^{9} .{ }^{1}$ Stanford University, Palo Alto, United States; ${ }^{2}$ University of Glasgow, Glasgow, United Kingdom; ${ }^{3}$ Swedish Medical Center and University of Washington, Seattle, United States; ${ }^{4}$ University of Cardiff, Cardiff, United Kingdom; ${ }^{5}$ University of Queensland, Brisbane, Australia; ${ }^{6}$ University of Bristol, Bristol, United Kingdom; ${ }^{7}$ MAPI Group, Houten, Netherlands: ${ }^{8}$ Novartis Pharmaceuticals Corporation, East Hanover, United States: ${ }^{9}$ Novartis Pharma AG, Basel, Switzerland

Background: Therapeutic options with discrete modes of action are now available for psoriatic arthritis (PsA). Clinicians require evidence to guide decision-making. No head-to-head RCTs have compared secukinumab 150 mg (SEC; anti-IL-17A) with infliximab $5 \mathrm{mg} / \mathrm{kg}$ (INF; TNFi) in patients with PsA. Matching-Adjusted Indirect Comparison (MAIC) can be used to estimate comparative effectiveness and enables treatment outcomes to be compared across effectively balanced trial populations. MAIC is an established method in health technology assessments, with NICE having recently published guidance.

Objectives: To use MAIC to assess the comparative effectiveness of SEC and INF for up to 1 year using pooled FUTURE 1 (F1) and FUTURE 2 (F2) individual patient data (IPD) and published aggregate IMPACT 2 data, respectively.

Methods: Pooled F1 and F2 data were used to maximize the effective sample size (ESS) for SEC. IPD from the SEC arms of F1 and F2 $(n=302)$ were weighted to match selected baseline characteristics of the INF arm of IMPACT $2(n=100)$. Placebo arms were also matched; placebo-adjusted comparisons were possible only until week 16 because patients could receive active treatment from this time point onwards. Logistic regression was used to determine weights for age, sex, race, body weight, methotrexate use, presence of psoriasis $(\geq 3 \%$ body surface area), mean PASI score, dactylitis, enthesitis, mean HAQ-DI score and previous TNFi therapy. Recalculated outcomes from F1 and F2 (SEC, ESS=91; placebo, ESS=59) were compared with data from IMPACT 2 (INF, $n=100$; placebo, $n=100$ ). Pairwise comparisons using odds ratios (ORs [95\% Cls]) were performed for ACR 20,50 and 70 responses at nearest-equivalent time points across trials: weeks 6/8, 14/16, 24 and 54/52. Mean changes from baseline in SF-36 Physical and Mental Component Summary (MCS) scores were also compared. Strict thresholds were avoided when interpreting $p$ values, in line with American Statistical Association 2016 guidance.

Results: There was no evidence of differences in ACR 20,50 and 70 responses between SEC and INF at weeks 6/8, 14/16 (both placebo-adjusted) and 24 (non-placebo-adjusted). At week 54/52, ACR 20 and 50 responses were higher with SEC than INF (OR [95\% CI]: 4.05 [1.98-8.30], $p<0.001$ and 1.90 [1.05-3.44], $p=0.034$, respectively). Improvements in SF-36 MCS scores were greater with SEC than INF at weeks $14 / 16(p=0.063), 24(p=0.001)$ and $54 / 52(p<0.001)$. A sensitivity analysis that added PsA duration, swollen joint count and CRP levels to the matching parameters yielded similar results.

Conclusions: In this MAIC, SEC showed evidence of superiority for symptomatic improvement (non-placebo-adjusted ACR 20 and 50) over INF for active PSA at 1 year. This was accompanied by greater improvements in SF-36 MCS scores. At earlier time points, there was no evidence of differences in ACR responses between SEC and INF.

Disclosure of Interest: V. Strand Consultant for: Abbvie, Amgen, AstraZeneca, Biogen Idec, Boehringer Ingelheim, Celltrion, Crescendo, Genentech/Roche, GSK, Janssen, Lilly, Merck, Novartis, Pfizer, Regeneron, Samsung, Sanofi and UCB, I. McInnes Consultant for: Abbvie, Celgene, Janssen, Novartis, Pfizer and UCB, P. Mease Grant/research support from: AbbVie, Amgen, BMS, Lilly, Novartis, Pfizer and UCB, Consultant for: AbbVie, Amgen, BMS, Corrona, Lilly, Merck, Novartis, Pfizer, Sun and UCB, Speakers bureau: AbbVie, Amgen, Celgene, Genentech, Novartis, Pfizer and UCB, E. Choy Grant/research support from: Pfizer, Roche and UCB, Consultant for: Chugai Pharma, Eli Lilly, Janssen, Novartis, Pfizer, Regeneron, Roche, R-Pharm and Sanofi, P. Nash Grant/research support from: Novartis, Consultant for: Novartis, Speakers bureau: Novartis, H.

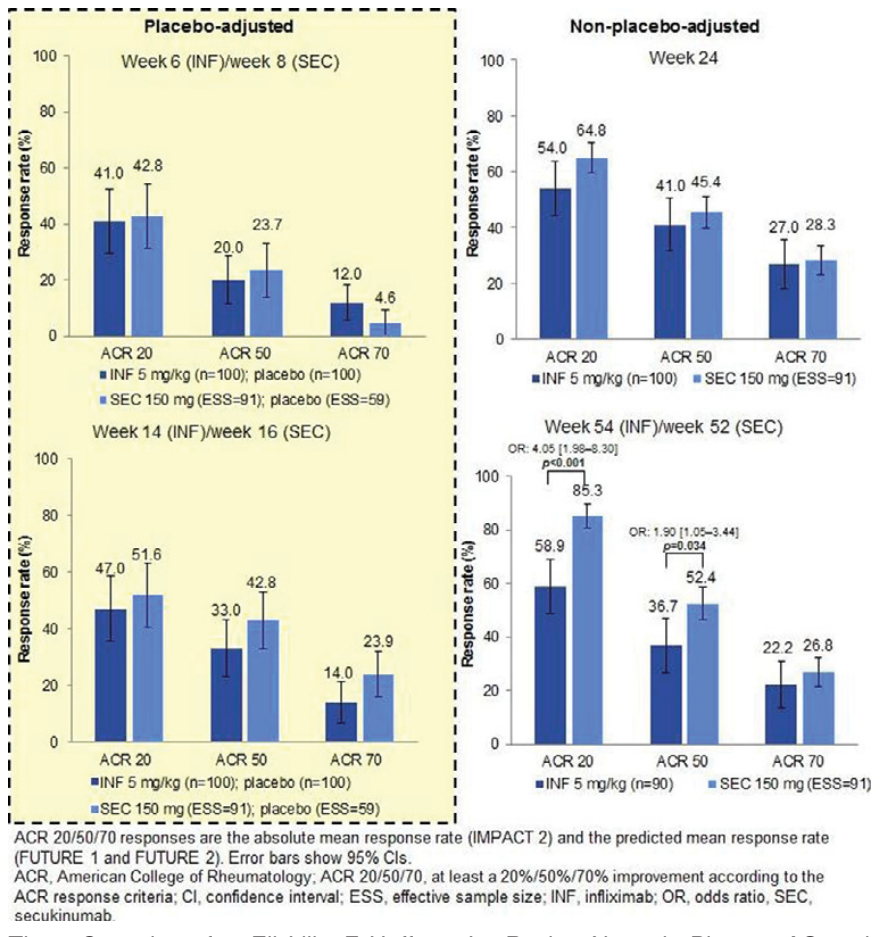

Thom Consultant for: Eli Lilly, F Hoffman-La Roche, Novartis Pharma AG and Pfizer, C. Kalyvas Employee of: Paid employee of the Mapi Group. The Mapi Group received funding from Novartis Pharma AG for this study, K. Gandhi Employee of: Novartis employee with stock, L. Pricop Employee of: Novartis employee with stock, S. Jugl Employee of: Novartis employee with stock DOI: 10.1136/annrheumdis-2017-eular.5802

\section{SAT0481 THE RELATIONSHIP BETWEEN THE PATIENT ACCEPTABLE SYMPTOM STATE (PASS) AND DISEASE ACTIVITY IN PATIENTS WITH PSORIATIC ARTHRITIS (PSA)}

J.Z. Fei ${ }^{1}$, A. Perruccio ${ }^{2}$, Y. Ye ${ }^{1}$, D.D. Gladman ${ }^{1}$, V. Chandran ${ }^{1} .{ }^{1}$ Rheumatology ${ }^{2}$ Orthopaedics, Toronto Western Hospital, Universtiy of Toronto, Toronto, Canada

Background: PASS is the highest level of symptoms beyond which patients consider themselves well. Psoriatic Arthritis Disease Activity Score (PASDAS) is a recently developed composite disease activity measure that summarizes a patient's disease in a single $0-10$ score.

Objectives: In this study, we aimed to identify the PASDAS cut-off points for PASS, and to examine the agreement between PASS and the PASDAS thresholds for low $(<3.2)$, moderate (3.2-5.4), and high disease activity $(>5.4)$.

Methods: Patients were prospectively recruited from the University of Toronto PsA clinic. A standard protocol including physician assessment and patient-reported outcomes was used to record variables required to calculate PASDAS. In addition, each patient was asked to "think about all the ways your PsA has affected you during the last 48 hours. If you were to remain in the next few months as you were during the last 48 hours, would this be acceptable to you?" to assess PASS. For analysis, the PASDAS threshold for PASS was identified with the ROC analysis to maximize specificity and sensitivity. Furthermore, the agreement between PASS and low, moderate, and high PASDAS disease activity cut-offs were evaluated. Results: 169 patients [ $61 \%$ male, mean age 56.1 , mean disease duration 16.9 years, mean (SD) PASDAS 3.25 (1.1)] were recruited. The PASDAS threshold for the patient acceptable symptoms state (PASS+) was identified to be 3.84 (AUC -0.88 , sensitivity 0.82 , specificity 0.94 ) using ROC curve analysis. $91 \%$ of patients with low disease activity (PASDAS $<3.2$ ) considered their symptoms state acceptable (PASS+), and $100 \%$ of the patients with high disease activity (PASDAS $>5.4$ ) considered their symptom state as unacceptable (PASS-). Furthermore, the mean (SD) PASDAS was 4.5 (1.0) in the PASS- group and 2.8 (1.1) in the PASS+ group

Conclusions: The PASDAS threshold for patient acceptable symptoms state is 3.84 , which is within the moderate disease activity range. Thus with a PASDAS of 3.84 or lower, PsA patients consider their symptom state acceptable for the next few months. This cut-off should be considered for shared decision making regarding treatments in PsA patients.

Disclosure of Interest: None declared

DOI: 10.1136/annrheumdis-2017-eular.6186 